\title{
Ocorrência de Cryptosporidium spp. em pequenos mamíferos silvestres de três áreas serranas do Sudeste brasileiro
}

\author{
[Occurrence of Cryptosporidium spp. in small wildlife mammals from three mountainous \\ areas in the Brazilian Southeastern region] \\ A.J. Dall'Olio ${ }^{1}$, R.M.B. Franco ${ }^{2 *}$ \\ ${ }^{1}$ Faculdades Integradas da Fundação de Ensino Octávio Bastos - São João da Boa Vista, SP \\ ${ }^{2}$ Departamento de Parasitologia, Laboratório de Protozoologia do Instituto de Biologia da UNICAMP \\ Caixa Postal 6109 \\ 13083-970 - Campinas, SP
}

\section{RESUMO}

Foi investigada a ocorrência de espécies de Cryptosporidium na fauna natural de pequenos mamíferos silvestres da Mata Atlântica de três áreas serranas do Sudeste brasileiro. Dos 240 animais capturados as fezes de 39 apresentaram estruturas álcool-ácido resistentes, detectadas pela coloração de Ziehl-Neelsen modificada. Pela reação de imunofluorescência direta foi confirmada a presença de oocistos de $C$. muris $(5,1 \%)$ e C. parvum $(5,1 \%)$, com infecção concomitante em dois animais. Apesar da baixa taxa de infecção, pequenos mamíferos silvestres podem ser reservatórios e veículos de infecção para outras espécies.

Palavras-chave: Cryptosporidium, pequenos mamíferos silvestres, roedores

\begin{abstract}
This study describes infection of Cryptosporidium spp in the natural fauna of small wildlife mammals in the Serra da Mantiqueira region. These protozoa were detected by a modified Ziehl-Neelsen technique and a direct immunofluorescent assay. From 240 captured animals, acid-resistant structures were observed in the feces of 39 specimens, and these structures were confirmed to be C. muris (5.1\%) or C. parvum (5.1\%) by the direct immunofluorescent assay.
\end{abstract}

Keywords: Cryptosporidium, small wildlife mammals, Rodentia

Bolsista de iniciação científica da FAPESP - Processo n. ${ }^{\circ}$ 00/004435-1 Recebido para publicação em 12 de dezembro de 2002

Recebido para publicação, após modificações, em 14 de julho de 2003

*Autor para correspondência

E-mail: mfranco@unicamp.br 


\section{INTRODUÇÃO}

Cryptosporidium é um protozoário que infecta a região das microvilosidades das células do epitélio intestinal e/ou a árvore brônquica de mais de 150 espécies de vertebrados (Fayer et al., 2000). Baseado em critérios morfológicos e de especificidade de hospedeiro, 21 espécies já foram descritas (O'Donoghue, 1995). No período de 1990 a 2001 foram relatadas as seguintes espécies com seus respectivos hospedeiros: $C$. parvum e $C$. muris, em mamíferos e roedores, respectivamente; $C$. meleagridis e $C$. baileyi em aves; $C$. serpentis e $C$. saurophillum, em répteis; C. nasorum, em peixes; C. felis, em felinos; $C$. wairi, em porquinho da índia; e C. andersoni, em bovinos (Thompson, 2002). Mais recentemente, duas novas espécies foram descritas: C. canis, em cães e $C$. molnari, em peixes (Xiao et al., 2000; 2002).

C. muris foi a primeira espécie descrita, em 1907 por Tyzzer, sendo seu desenvolvimento endógeno restrito às glândulas estomacais de roedores. C. parvum, também descrita por Tyzzer (1912), ocorre principalmente no intestino delgado de vários mamíferos, incluindo o homem. Até meados de 1998 C. parvum foi considerada como a única espécie de relevância em saúde pública (Tzipori, Griffiths, 1998). Recentemente, infecções envolvendo outros genótipos e espécies (C. muris e C. meleagridis) foram detectadas em pessoas que apresentavam ou não comprometimento do sistema imunológico (Katsumata et al., 2000; Pedrazadiaz et al., 2000).

Cryptosporidium é transmitido entre indivíduos por meio de oocistos que já são eliminados na forma infectante, sendo as principais vias de transmissão o contato direto (pessoa-a-pessoa) ou indiretamente pela ingestão de alimentos ou água contaminada. A dose mínima infectante varia de 9 a 1042 oocistos, dependendo da amostra (Fayer et al., 2000). O comprometimento do sistema imunológico do hospedeiro é um fator fundamental na definição do curso clínico da criptosporidiose.

A importância da veiculação hídrica da criptosporidiose foi reconhecida a partir do grande surto de Milwaukee, Wisconsin, em 1993, onde 403.000 pessoas foram contaminadas e dessas, 4.400 foram hospitalizadas, havendo 100 óbitos, 69 em pacientes VIH-positivos (Solo-Gabriele, Neumeister, 1996; Fayer et al., 2000). Desde então, numerosos surtos de criptosporidiose devido à ingestão de água contaminada foram relatados ao redor do mundo (Rose, 1997) e a proteção dos mananciais é considerado como o melhor método de controle da infecção por Cryptosporidium (Solo-Gabriele, Neumeister, 1996).

A criptosporidiose já foi registrada em roedores silvestres e a ausência de especificidade para o hospedeiro sugere que esses pequenos mamíferos podem ser reservatórios da parasitose (Sinski et al.,1998). Entretanto, o potencial zoonótico de Cryptosporidium a partir de hospedeiro silvestre é ainda pouco estudado no Brasil.

Este trabalho investigou a ocorrência da infecção por Cryptosporidium parvum e/ou C. muris em pequenos mamíferos silvestres da Mata Atlântica (complexo Serra da Mantiqueira).

\section{MATERIAL E MÉTODOS}

A pesquisa foi realizada em três áreas serranas (Fig. 1) do Sudeste brasileiro: no Parque Nacional do Itatiaia (PNI, localizado na divisa dos estados de Minas Gerais e Rio de Janeiro, a uma altitude média de $1.100 \mathrm{~m}$; S22 $26.019^{\prime} / \mathrm{W} 44^{\circ} 37.687^{\prime}$; cidade referência: Itatiaia, RJ), na Serra da Bocaina (SB, localizada entre os estados de São Paulo e Rio de Janeiro, a uma altitude média de $1.460 \mathrm{~m}$; S22 ${ }^{\circ} 44.034^{\prime} / \mathrm{W} 44^{\circ} 36.662^{\prime}$; cidade referência: São José do Barreiro) e na Serra da Fartura (SF, no complexo Serra da Mantiqueira em São João da Boa Vista, SP, a uma altitude média de 1.010m.; S22 ${ }^{\circ} 53.650^{\prime} / \mathrm{W}^{\prime} 6^{\circ} 45.049^{\prime}$ ).

Essas áreas são pequenos fragmentos de Mata Atlântica ainda existentes no Sudeste, constituídos por mata primária cujos arredores sofreram profundas modificações no meio ambiente. $\mathrm{Na} \mathrm{SB}$ e na $\mathrm{SF}$, devido à proximidade com propriedades agrícolas, acontecem invasões ocasionais das matas por animais domésticos. 


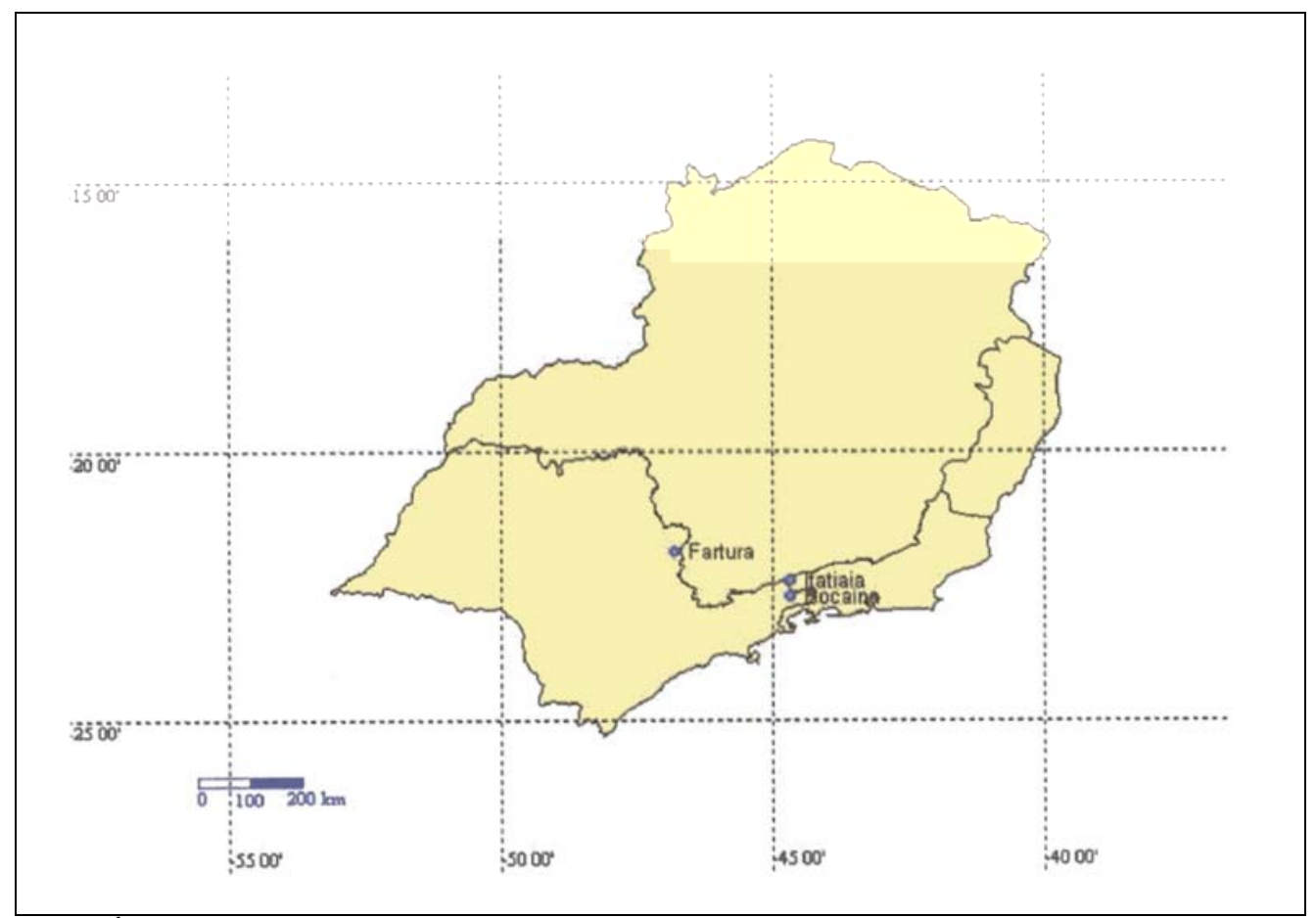

Figura 1. Áreas da pesquisa: Parque Nacional do Itatiaia, Serra da Bocaina e Serra da Fartura, localizadas na região Sudeste brasileira.

As capturas foram trimestrais com duração de cinco dias cada; no primeiro dia, era feita a montagem das armadilhas e, nos subseqüentes, a captura dos pequenos mamíferos. Foram utilizadas 100 armadilhas do tipo Sherman (50 grandes e 50 pequenas) dispostas de modo a formar uma grade de 100 pontos. Para isso, foram abertas 10 trilhas paralelas, distantes 20 metros uma da outra, com cada trilha contendo 10 pontos de colheita, com 20 metros de distância entre eles. Cada ponto foi marcado com uma estaca de 50 centímetros de comprimento e as estacas foram numeradas de 00 a 99. Foram utilizadas como iscas banana e mandioca com creme de amendoim.

Os animais foram capturados vivos e submetidos ao procedimento-padrão de retirada do animal da armadilha, pesagem, determinação do sexo, medição e marcação com brinco de identificação e soltura no mesmo ponto de captura. As fezes, colhidas nas armadilhas, foram mantidas em tubos com solução de dicromato de potássio $2,5 \%$, na proporção de $3: 1$. As recapturas de animais no mesmo período de colheita foram ignoradas e as de colheitas anteriores seguiram o procedimento padrão.

Transportadas em condições adequadas para o laboratório de protozoologia do Instituto de Biologia, Unicamp, as amostras de fezes foram então homogeneizadas e concentradas a $500 \mathrm{xg}$ (10mim). Com os sedimentos foram feitos esfregaços corados pela técnica de Ziehl-Neelsen modificada (ZNm) (Henriksen, Pohlenz, 1981) e examinados ao microscópio óptico com aumento de $1000 x$.

Alíquotas das amostras que apresentaram estruturas álcool-ácido-resistentes, pela $\mathrm{ZNm}$ com tamanho e formato similares aos de oocistos de Cryptosporidium (medidas realizadas com auxílio de ocular micrométrica) foram reexaminadas, utilizando-se a técnica de imunofluorescência direta (IFA) com anticorpos monoclonais ${ }^{1}$ para a confirmação específica de C. parvum e C. muris.

\footnotetext{
${ }^{1}$ Kit Merifluor, Meridian Diagnostics, Cincinnatti, Ohio
} 
Para tanto foram feitas modificações no procedimento descrito por Deng e Cliver (1999), como se segue: após sucessivas lavagens por centrifugação e concentração em água destilada contendo Tween 80 a $1 \%$ (Hd-T), os sedimentos foram transferidos para tubos cônicos aos quais adicionou-se solução de Sheather (gravidade específica de $1,20 \mathrm{~g} / \mathrm{ml}$ ); após centrifugação (500xg; 8min), a camada superior $(2 \mathrm{ml})$ foi cuidadosamente colhida e lavada em Hd-T (650xg, 10min) e dos sedimentos resultantes, alíquotas de $5 \mu \mathrm{l}$ foram examinadas por meio de IFA, de acordo com as instruções do fabricante. Para a leitura do teste de imunofluorescência foram utilizados filtro de excitação de 450$490 \mathrm{~nm}$ e filtro de barreira de 520nm. Foram considerados como critérios de positividade o grau de fluorescência verde-maçã brilhante, predominante na parede, a presença de sutura, o formato e o tamanho dos oocistos.

\section{RESULTADOS}

Foram capturados 240 animais nas três áreas de estudo, sendo $153(63,8 \%)$ machos e $87(36,2 \%)$ fêmeas. O número de espécimes recapturados em diferentes períodos foi de cinco (Tab. 1).

Tabela 1. Espécies e sexo de pequenos mamíferos silvestres capturados e recapturados nas três áreas serranas entre março de 2000 e fevereiro de 2001

\begin{tabular}{lccc}
\hline Espécie & $\begin{array}{c}\mathrm{N}^{\circ} \mathrm{de} \\
\text { machos }\end{array}$ & $\begin{array}{c}\mathrm{N}^{\circ} \mathrm{de} \\
\text { fêmeas }\end{array}$ & $\begin{array}{c}\mathrm{N}^{\circ} \mathrm{de} \\
\text { recapturas }\end{array}$ \\
\hline Akodon montensis & 52 & 31 & 2 \\
Akodon serrensis & 49 & 22 & 1 \\
Delomys sublineatus & 10 & 10 & 2 \\
Delomys dorsalis & 8 & 5 & \\
Trinomys dimediatus & 2 & 3 & \\
Thaptomys nigrita & 2 & 1 & \\
Marmosops incanus & 2 & & \\
Oligoryzomys sp. & 12 & 3 & \\
Philander frenata & 4 & 3 & \\
Oxymyterus sp. & 5 & 2 & \\
Didelphis aurita & 2 & 2 & \\
Thylamys sp. & 3 & 5 & \\
Monodelphis americana & 1 & & \\
Nectomys squamipes & 1 & & \\
Total & 153 & 87 & 5 \\
\hline
\end{tabular}

Não se observou alteração na consistência fecal.
Organismos álcool-ácido resistentes, com tamanho e coloração semelhantes aos de oocistos de Cryptosporidium, foram detectados nas fezes de 39 animais (16,3\%), ocorrendo em pequeno número nas preparações examinadas $(2$ a 5 organismos/100 campos microscópicos). As medidas desses organismos situaram-se ao redor de $5,0 \times 4,1 \mu \mathrm{m}$ e de $7.9 \times 6,3 \mu \mathrm{m}$, sugerindo uma infecção mista por $C$. parvum e C. muris (Tab. 2).

Tabela 2. Dimensões dos oocistos (média e variação) detectados em amostras fecais dos pequenos mamíferos silvestres capturados em três áreas serranas do Sudeste brasileiro (20002001), comparativamente às medidas de referência para C. muris e C. parvum

\begin{tabular}{lccc}
$\begin{array}{l}\text { Espécie de } \\
\text { Cryptosporidium }\end{array}$ & $\begin{array}{c}\text { Comprimento } \\
(\mu \mathrm{m})\end{array}$ & $\begin{array}{c}\text { Largura } \\
(\mu \mathrm{m})\end{array}$ & $\begin{array}{c}\text { Índice de } \\
\text { forma* }^{*}\end{array}$ \\
\hline C. muris $(\mathrm{n}=29)$ & $7,9[8,0-6,5]$ & $6,3[7,0-5,5]$ & 1,26 \\
C.parvum $(\mathrm{n}=18)$ & $5,0[6,5-5,0]$ & $4,1[4,0-3,5]$ & 1,21 \\
C. muris* & $8,4[9,2-8,0]$ & $6,2[6,4-5,8]$ & $1,25-1,59$ \\
C. parvum* & $5,2[5,6-4,8]$ & $4,6[4,8-4,2]$ & $1,04-1,33$ \\
\hline *De acordo com Xiao et al. $(2000)$.
\end{tabular}

A positividade para oocistos de Cryptosporidium spp. nas áreas de colheita variou de $14,0 \%$ a $25,0 \%$ (Tab. 3), e as espécies de pequenos mamíferos capturadas (Ordens Rodentia e Marsupialia) variaram em cada região (Tab. 1).

Tabela 3. Número de pequenos mamíferos silvestres capturados por região estudada e positividade para Cryptosporidium spp., detectada pela coloração de Ziehl-Neelsen modificada

\begin{tabular}{lcccc}
\hline Região & $\begin{array}{c}\mathrm{N}^{0} \text { de animais } \\
\text { capturados* }\end{array}$ & $(\%)$ & $\begin{array}{c}\mathrm{N}^{0} \text { de animais } \\
\text { positivos }\end{array}$ & $(\%)$ \\
\hline SF* $^{*}$ & 64 & $(26,6)$ & 9 & $(14,06)$ \\
$\mathrm{PNI}$ & 48 & $(20,0)$ & 12 & $(25,0)$ \\
$\mathrm{SB}$ & 128 & $(53,3)$ & 18 & $(14,06)$ \\
Total & 240 & $(100,0 \%)$ & 39 & $(16,25 \%)$ \\
\hline * SF= Serra da Fartura; & $\mathrm{PNI}=$ Parque Nacional do Itatiaia; \\
$\mathrm{SB}=$ Serra da Bocaina.
\end{tabular}

Quando consideradas apenas as amostras nas quais as estruturas álcool-ácido-resistentes foram detectadas $(n=39)$, foi possível confirmar com a utilização de IFA a presença de oocistos de Cryptosporidium em quatro animais $(10,3 \%)$, sendo dois (Akodon serrensis; Oryzomys ratticeps) positivos para $C$. parvum $(5,1 \%)$ e dois (Akodon serrensis) positivos para $C$. muris e $C$. parvum concomitantemente $(5,1 \%)$.

Arq. Bras. Med. Vet. Zootec., v.56, n.1, p.25-31, 2004 


\section{DISCUSSÃO}

Até o momento não se tem registro no país da existência de levantamentos similares sobre a infecção de pequenos mamíferos silvestres (Ordens Rodentia e Marsupialia) por Cryptosporidium. As dificuldades encontradas foram muitas devido ao pouco conhecimento existente sobre esses animais no Brasil, à escassez de inventários faunísticos e aos problemas relativos à taxonomia dos marsupiais e roedores de pequeno porte (Emmons, 1997; Bergallo et al., 2000).

As áreas serranas estudadas são reservas florestais pertencentes à Mata Atlântica que, apesar de ser uma das regiões mais afetadas pela ação humana, ainda apresenta alta diversidade de mamíferos, sendo considerada como o ecossistema com a maior biodiversidade do planeta. Reduzida a 5\% de sua área original, a atividade antrópica produziu acentuado efeito negativo sobre as populações animal e vegetal (Bergallo et al., 2000).

Um dos principais problemas na detecção de Cryptosporidium nos pequenos vertebrados dessas áreas é a distinção entre os oocistos e outros elementos presentes nas fezes como fungos, leveduras e restos de frutos e folhas que servem de alimento para eles (Abranches et al., 1998).

$\mathrm{O}$ fato dos animais apresentarem infecção assintomática, a julgar pela consistência das fezes, e o pequeno número de oocistos presente (2 a 5 oocistos/100 campos microscópicos) exigem o emprego de técnicas mais sensíveis de diagnóstico. A técnica empregada neste estudo (IFA, após concentração prévia em solução de Sheather) permite a detecção de cerca de 200 oocistos/g de fezes, como comprovado em inoculações experimentais (Deng, Cliver, 1999), enquanto o método clássico de detecção de Cryptosporidium (centrifugação e concentração a $500 \times g$ e coloração de $\mathrm{ZNm}$ ) apresenta alto limiar de detecção para fezes formadas e baixa sensibilidade (Weber et al., 1992). A utilização da IFA confirmou não só a ocorrência de criptosporidiose subclínica como também a presença de duas espécies diferentes do protozoário (C. muris e C. parvum), isso pela visualização de graus distintos de fluorescência da parede dos oocistos e identidade do tamanho com os padrões de referência para $C$. parvum $\mathrm{e}$ C. muris.

Estudos anteriores (Graczyk et al., 1996; Garcia et al., 1997) demonstraram que o kit Merifluor detecta positivamente $C$. muris e não apresenta problema de reatividade cruzada (Garcia et al., 1987). Como apenas as amostras onde haviam sido identificadas estruturas álcool-ácido resistentes $(n=39)$ foram submetidos à IFA, é possível que a ocorrência de criptosporidiose detectada neste estudo $(16,2 \%)$ tenha sido subestimada. No entanto, o aspecto mais importante é o achado de oocistos de C. muris e C. parvum nas fezes dos pequenos mamíferos silvestres, sugerindo que eles pudessem atuar como reservatórios da criptosporidiose e concorrer para a contaminação dos cursos d'água e a infecção de outros animais, entre eles os mamíferos invasores (Mus musculus; Rattus rattus, $R$. norvergicus, Myocastor sp.) e destes, a transmissão para o homem.

Das duas espécies identificadas, a infecção por C. muris é menos freqüente do que $C$. parvum (Chalmers et al., 1997; Sinski et al., 1998; Sturdee et al., 1999; Torres et al., 2000) o que também foi visto neste estudo, quando se utilizou a IFA.

Roedores e insetívoros (A. sylvaticus, C. russula) foram apontados como os principais pequenos mamíferos silvestres envolvidas na disseminação de Cryptosporidium no nordeste da Espanha (Torres et al., 2000). Chalmers et al. (1997) detectaram prevalências de $22 \%, 21 \%$ e $13 \%$ para C. parvum em Mus domesticus, A. sylvaticus e Clethrionomys glareolus, respectivamente. A positividade para C. muris foi menor $(10 \%, 6 \%$ e $2 \%)$. Na Polônia, Sinski (1993) determinou que C. glareolus (20\%) e outros roedores silvestres atuam como reservatórios de Cryptosporidium. Posteriormente, Sinski et al. (1998), também utilizando esfregaços fecais corados pelo método de $\mathrm{ZNm}$, registraram várias espécies de roedores silvestres abrigando $C$. parvum, mas com baixa intensidade de infecção. Na Inglaterra, Sturdee et al. (1999) assinalaram ampla distribuição do protozoário entre mamíferos silvestres (22/184), mas não detectaram $C$. muris.

O fato de que, neste estudo, a infecção por $C$. parvum, comprovada pela IFA, foi registrada em 
maior número de animais capturados, sugere que essa possa ser atualmente a espécie predominante entre os pequenos mamíferos silvestres das regiões estudadas. De acordo com Bull et al. (1998), a espécie é freqüentemente detectada entre os roedores silvestres, enquanto que $C$. muris constitui um achado raro, principalmente em regiões que sofreram o impacto da ação antrópica. É interessante salientar que estes autores constataram que C. muris foi a espécie predominante entre ratos de uma ilha onde, desde a década de 50 , não se registrava a presença de gado. Estudos de infecção experimental evidenciaram que amostras de $C$. muris obtidas de camundongos infectam outros animais (cães, porquinho da índia, coelhos, ovelhas), porém sem produzir sinais clínicos (Aydin, Ozkul, 1996).

No Brasil, a infecção por C. muris foi relatada no gado bovino, tanto em animais jovens como adultos (Ogassawara et al., 1989; Pena et al., 1997). Recentemente, C. muris de bovinos foi considerada geneticamente distinta, recebendo a denominação de $C$. andersoni (Lindsay et al., 2000).

No caso dos animais capturados e examinados neste estudo, a maioria tem por hábitat florestas primárias ou secundárias, associado ou não à água mas, por viverem dentro de reservas nacionais, o contato direto com animais domésticos ou ambientes modificados pelo homem é eventual, o que explicaria a baixa positividade encontrada $(5,1 \%$ para ambas as espécies).

Do ponto de vista biológico, é interessante ressaltar a ocorrência de infecção concomitante por $C$. muris e $C$. parvum em dois animais, uma vez que $C$. muris apresenta diferente sítiolocalização em relação a C. parvum.

\section{REFERÊNCIAS BIBLIOGRÁFICAS}

ABRANCHES, J.; NÓBREGA, H.N.; VALENTE, P. et al. A preliminary note on yeasts associated with fecal pellets of rodents and marsupials of Atlantic forest fragments in Rio de Janeiro, Brazil. Rev. Microbiol., v.29, p.170-173, 1998.
AYDIN, Y.; OZKUL, L.A. Infectivity of Cryptosporidium muris directly isolated from the murine stomach for various laboratory animals. Vet. Parasitol., v.66, p.257-262, 1996.

BERGALLO, H.G.; ROCHA, C.F.D.; ALVES, M.A.S. et al. (Eds.) A fauna ameaçada de extinção do Estado do Rio de Janeiro. Rio de Janeiro: UERJ/FAPERJ, 2000. 168p.

BULL, S.A.; CHALMERS, R.M.; STURDEE, A.P. et al. A survey of Cryptosporidium species in skomer bank voles (Clethrionomys glareolus skomerensis). J. Zool., v.244, p.119-122, 1998.

CHALMERS, R.M.; STURDEE, A.P.; BULL, S.A. et al. The prevalence of Cryptosporidium parvum and C. muris in Mus domesticus, Apodemus sylvaticus and Clethrionomys glareolus in an agricultural system. Parasitol. Res., v.83, p. 478-482, 1997.

DENG, M.Q.; CLIVER, D. O. Improved Immunofluorescense Assay for detection of Giardia and Cryptosporidium from asymptomatic adult cervine animals. Parasitol. Res., v.58, p.733-736, 1999.

EMMONS, L.H. Neotropical rainforest mammals. A Field Guide. 2.ed. University Chicago, 1997.

FAYER, R.; MORGAN, U.; UPTON, S.J. Epidemiology of Cryptosporidium: transmission, detection and identification. Int. J. Parasitol., v.30, p.12-13, 2000.

GARCIA, L. S.; BREWER, T.C.; BRUCKNER, D.A. Fluorescence detection of Cryptosporidium oocysts in human fecal specimens by using monoclonal antibodies. J. Clin. Microbiol., v.25, p.119-121, 1987.

GARCIA, L.S.; SHIMIZU, R. Y. Evaluation of nine immunoassay kits (Enzyme Immunoassay and Direct Fluorescence) for detection of Giardia lamblia and Cryptosporidium parvum in human fecal specimens. J. Clin. Microbiol., v.35: p.1526-1529, 1997.

GRACZYK, T.K.; CRANFIELD, M.R.; FAYER, R. Evaluation of commercial enzyme immnuassay (EIA) and immunofluorescent antibody (IFA) test kits for detection of Cryptosporidium oocysts of species other than Cryptosporidium parvum. Am. J. Trop. Med. Hyg., v.54, p.274-279, 1996. 
HENRIKSEN, S.A.; POHLENZ, J.F.L. Staining of Cryptosporidia by a modified Ziehl-Neelsen technique. Acta Vet. Scand., v.22, p.594-596, 1981.

KATSUMATA, T.; HOSEA, D.; RNUH, I.G. et al. Possible Cryptosporidium muris infection in humans. Am. J. Trop. Med. Hyg., v.62, p.70-72, 2000 .

LINDSAY, D.S.; UPTON, S.J.; OWENS, D.S. et al. Cryptosporidium andersoni n. sp. (Apicomplexa: Cryptosporiidae) from cattle, Bos taurus. J. Eukaryot. Microbiol., v.47, p.91-95, 2000.

O'DONOGHUE, P. J. Cryptosporidium and cryptosporidiosis in man and animals. Int. J. Parasitol., v.25, p.139-195, 1995.

OGASSAWARA, S.; CASTRO, J.M.; KASAI, N. et al. Cryptosporidium tipo C.muris em bovinos do Estado de São Paulo (Nota Prévia). In: Anais Seminário Brasileiro de Parasitologia Veterinária, 6, Bagé, RS, 1989. 25 a 29 setembro. pp.123.

PEDRAZA-DIAZ, S.; AMAR, C.; McLAUCHLIN, J. The identification and characterization of an unsual genotype of Cryptosporidium from human faeces as Cryptosporidium meleagridis. FEMS. Microbiol. Lett., v.189, p.189-194, 2000.

PENA, H.F.J.; KASAI, N.; GENNARI, S.M. Cryptosporidium muris in dairy cattle in Brazil. Vet. Parasitol., v.73, p.353-355, 1997.

ROSE, J.D. Environmental ecology of Cryptosporidium and public health implications. Annu. Rev. Public Health, v.18, p.135-161, 1997.

SINSKI, E. Cryptosporidiosis in Poland: clinical, epidemiologic and parasitologic aspects. Folia Parasitol., v.40, p.297-300,1993.
SINSKI, E.; BEDNARSKA, M.; BAJER, M. The role of wild rodents in ecology of Cryptosporidiosis in Poland. Folia Parasitol., v.45, p.173-174, 1998.

SOLO-GABRIELE, H.; NEUMEISTER, S. US outbreaks of cryptosporidiosis. J. $A W W A$, v.88, p.76-86, 1996.

STURDEE, A.P.; CHALMERS, R. M.; BULL, S.A. Detection of Cryptosporidium oocysts in wild mammals of mainland Britain. Vet. Parasitol., v.80, p.273-280, 1999.

THOMPSON, R.C.A. Presidential address: rediscovering parasites using molecular towards revising the taxonomy of Echinococcus, Giardia and Cryptosporidium. Int. J. Parasitol., v.32, p.493-496, 2002.

TORRES, J.; GRACENEA, M.; GÓMEZ, M.S. et al. The occurrence of Cryptosporidium parvum and $C$. muris in wild rodents and insectivores in Spain. Vet. Parasitol., v.92, p. 253-260, 2000.

TZIPORI, S.; GRIFFTHS, J.K. Natural history and Biology of Cryptosporidium parvum. Advanc. Parasitol., v.40, p.6-29, 1998.

WEBER, R.; BRYAN, R. T.; JURANEK, D.D. Improved stool concentration procedure for detection of Cryptosporidium oocysts in fecal specimens. J. Clin. Microbiol., v.30, p.28692873, 1992.

XIAO, L.; MORGAN, U.M.; FAYER, R. et al. Cryptosporidium systematics and implications for public health. Parasitol. Today, v.16, p.287292, 2000.

XIAO, L.; SULAIMAN I.M.; RYAN, U.M. et al. Host adaptation and host-parasite co-evolution in Cryptosporidium: implications for taxonomy and public health. Int. J. Parasitol., v.32, p.17731795, 2002. 